\title{
La creación en el Popol Vuh
}

\author{
José Ignacio González Faus \\ Facultad de Teología de Cataluña, \\ Centro de Reflexión Teológica, San Salvador.
}

Advertencia previa. El objetivo de estas líneas es más modesto de lo que su título puede sugerir. Intentan sólo una comparación material, entre el texto del Popol Vuh y el del Génesis, para constatar una serie de semejanzas y desemejanzas, cuyo sentido pleno ya no me considero capaz de establecer. En definitiva es la lectura de un occidental, habituado a la Biblia, que se acerca al libro con curiosidad y simpatía; sin conocimiento directo de las sociedades en que ha nacido; sin competencias para contextuarlo, ni tampoco para fijar exactamente su texto. Pero lamentando que sobre el Popol Vuh se haya escrito mucho más desde la antropología cultural que desde la teologíal.

Acepto pues la información habitual de que el texto fue escrito poco después de la conquista (en la primera mitad del XVI) por un grupo de sabios quichés que recogian tradiciones mucho más antiguas, conservadas por memoria oral, y quizá también con la ayuda de códices de amate. El textus receptus u oficial fue transmitido por fray Francisco de Ximénez, a quien los indígenas lo confiaron por amistad en 1688. Existe la sospecha de que Ximénez introdujo algunas correcciones o añadidos. También parece lo más coherente que dichas modificaciones - si existieron - se hiciesen para cristianizar al libro y no para desautorizarlo. As! lo sugiere la amistad del fraile con los nativos, y su deseo de salvar al texto, frente a otros libros sagrados precolombinos, que fueron destruidos por el fanatismo de los conquistadores.

Esta sospecha de ambigüedad se refleja ya en el prólogo, donde se comienza diciendo que contiene una manifestación y "revelación", para añadir en el párrafo siguiente: "esto lo escribiremos ya dentro de la ley de Dios, en el cristianismo" (p. 31)2. Tal ambigüedad puede volver cuestionables algunas de las semejanzas que mi lectura llegue a encontrar; y aqui habrá que dejar la palabra a los expertos. 
A pesar de todo, es así como el Popol Vuh ha seguido presente entre los pueblos mayas hasta hoy, y ello puede dar cierta utilidad a este esfuerzo comparativo.

\section{Creación de la tierra}

El capítulo primero de la obra invita, por su mismo tono, a ser leldo en paralelo con el primer capílulo del Génesis, aunque la Biblia va directamente a la creación ("en el principio creó Dios"), y el Popol Vuh se entretiene en una especie de momento previo a ella: "Esta es la relación de cómo todo estaba en suspenso, todo en calma, todo en silencio... y vacía la extensión de la tierra" (p. 35). Pero nolemos que también el Génesis, en el v. 2, parećáa volverse a ese momento previo calificándolo como un caos informe.

Con ello tendríamos un vacío pacífico (Popol Vuh) frente a un vacío caótico (Génesis). Esto puede tener que ver con el hecho de que Génesis l, escrito en el destierro, intenta universalizar la experiencia judía ${ }^{3}$, mientras que el Popol Vuh se atiene más a aquel pueblo concreto, por lo que estarfa más en la línea de Génesis 5 ("esta es la descendencia de Adán" etc.) que se considera cronológicamente anterior a Génesis 1.

Puede darse por sentado que ambos hagiógrafos concebian cielo y tierra como dos planos cuadrangulares superpuestos ${ }^{4}$, a los que luego (con la experiencia de la muerte) se les añadirá un tercer cuadrángulo "infernal" (en el sentido etimológico de inferior o subterráneo). Esta concepción es tan elemental que está muy extendida y subyace a infinidad de cosmovisiones primitivas. Pero, como ya hemos advertido, no entraremos en este punto, sino que vamos directamente a una lectura simultánea de los dos textos, que nos revelará una serie de elementos coincidentes. Por ejemplo:

\section{Acercamientos}

1) La prioridad de las aguas y el problema de la aparición de la tierra. En el Génesis esa prioridad de las aguas parece importada del mundo mesopotámico, mientras que en el Popol Vuh debe ser reflejo de la geografía ambiental. No sé si debido a esto, el Popol Vuh ve la aparición de la tierra ya como separación, ya como emergencia desde las aguass, mientras que el Génesis $(1,6.7)$ la concibe sólo como separación.

2) La aparición de la luz parece haber sido un problema para ambos hagiógrafos: para Génesis 1, 3 está ahí el comienzo de la creación. Para el Popol $V u h$ "conferenciaron sobre la vida y la claridad, cómo se hará para que aclare y amanezca" (p. 36). Hay aquí una profunda experiencia metafísica, en una situación cultural carente de instrumentos conceptuales para expresarla. 
3) También el orden de las dos cosmogonías es relativamente similar: luz, agua, tierra, plantas, animales, hombre.

4) En ambos aparece una creación por la palabra que modifica a otra concepción más artesana: al "dijo Dios" del Génesis puede corresponderle el "hágase así... Así dijeron... ¡Tierra!, dijeron, y al instante fue hecha" (p. 36). ¿Puede estar aquí la mano del buen fraile Ximénez? No es en absoluto necesario: hay también mitos egipcios que conocen la acción de la palabra divina sobre algún material preexistente. Pero hay que añadir que, para la reflexión bíblica posterior, la creación por la palabra no es sólo cuestión de poder, sino expresión de una intención comunicadora: Dios crea "por Su Palabra" para darse un interlocutor que será "el ser de la palabra": el hombre. Como iremos viendo, el Popol Vuh no está lejano a esta concepción.

5) En ambos la creación es buena y agrada a sus Autores. En los dos hay una especie de deliberación para crear al hombreb. Y en ambos aparece afirmada la prinacia del hombre: tan clara en Génesis 1, 26-29 como en esla preciosa frase del Popol Vuh: "no habrá gloria ni grandeza en nuestra creación y formación hasta que exista la creatura humana, el hombre formado" (p. 36).

\section{Diferencias}

Si ahora hubiese que señalar alguna diferencia, llaman la atención éstas:

1) En el Popol Vuh no se habla de la creación de los astros, pero el Génesis ha tenido que dedicarles un día ínlegro de su creación (1, 14-17), en probable polémica con las cosmogonlas ambientales, para desdivinizarlos y reducirlos a simples creaturas.

2) El Popol Vuh es mucho más concreto al hablar de los árboles ("cipresales y pinares" p. 36), mientras que el Génesis habla mucho más genéricamente de "hierba y frutales". Posiblemente se reflejan aquí las geografías originarias de cada texto.

3) Finalmente está el problema del poliseismo o de los "seres divinos" que es el que resulta más difícil de resolver para un lector de fuera. Rafael Girard (p. 29) cita otro texto del Chilam Balam de Chumayel que me parece más clara. mente monoteísta. Si nos limitamos a los dos textos que aquí estamos comparando, cabe decir que el Génesis sólo utiliza una vez el plural deliberativo $(1,26$ para la creación del hombre), el cual es mucho más frecuente en el Popol Vuh. Este parece concebir que la creación es obra de "el Creador, el Formador y los Progenitores" (p. 38). Como si Dios hiciera emanar de sf a los otros dioses que son los que actúan como demiurgos. $Y$ no sé si la preciosa expresión monoteísta: "existía el cielo y también el Corazón del Cielo, que éste es el nombre de Dios" (p. 35), queda suavizada en la página siguiente, por la mención de Caculhá-Huracán, Chipi-Caculhá y Raxá-Caculhá (el relámpago, el rayo 
pequeño y el rayo verde -0 el trueno- según la interpretación de Ximénez), de los que el autor del Popol Vuh comenta: "y estos tres son el Coraz6n del Cielo"7.

\section{De la tierra al hombre}

En ambos textos, la creación del mundo se encamina al hombre y concluye en él. Es fácil constatar que en el Popol Vuh la aparición del hombre es todavía más seria y más trabajosa que en el Génesis. Las deliberaciones de la divinidad se multiplican y se hacen necesarios varios intentos o esbozos previos. Aunque el Génesis contiene dos narraciones (el hombre de barro del caṕltulo 2 y el hombre "imagen" del capílulo 1), no se puede decir que el primero fuera un intento del segundo.

Para el Popol Vuh no sólo serán necesarios varios empeños, sino que ya los animales aparecen como intentos fallidos del hombre: son creados para guardar la creación anterior. Guardar es un verbo preferible a la actual tradición de nuestras biblias respecto de Adán (dominar: Génesis 1, 28). Quizá no sea exagerado insinuar que ambos verbos reflejan mentalidades y pueden tener consecuencias prácticas muy distintas: por el lado israelita, progreso y destrucción de la creación; por el lado maya, cierto fixismo y respeto ecológico.

Además de eso, los animales son creados para hablar: para que, de este

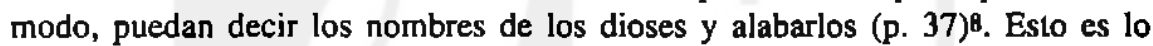
que no consiguen y por ello serán castigados: el Popol Vuh parece justificar as! la alimentación carnivora9, que en el Génesis aparece mucho más tarde, a raíz del diluvio y cuando ya el hombre está implantado en la historia ( $c f r$ Génesis 9 , 3ss).

En conclusión, se hace necesario un nuevo intento, en el cual se proclama la finalidad del hombre, sin mencionar ahora lo de "guardar" la tierra, y definiéndolo de cara a sus Progenitores divinos. El Popol Vuh multiplica aquí los verbos: el hombre existirá para sustentarlos, alimentarlos, invocarlos, recordarlos, alabarlos y venerarlos ( $f f r$. p. 38). Una mentalidad bíblica, a la vez que admira la profunda religiosidad de este párrafo, puede echar de menos aquí el "horizontalismo" que inclufa la idea bßlica de "dominio": el verdadero servicio a Dios es llevar adelante su creación hasta que llegue su reino. Con ello se percibe que, en el dominio del hombre, se trata para la Biblia de un dominio obediente y no absoluto, como se refleja en su limitación por el "árbol de la ciencia" (sea cual sea el significado de éste).

Pero en este nuevo intento vuelve a comenzar la dificultad de los Progenitores celestes por dar a luz al hombre. $\mathrm{Y}$ asistimos a la aparición de los diversos tipos de hombre, que es uno de los rasgos más conocidos del poema maya. Esos diversos tipos son primero el hombre de barro, luego el de madera y finalmente 
el de diversas plantas. No sé si una mentalidad concordista podrfa empeñarse en descubrir ahí una concepción transformista y un anuncio de los diversos tipos de homínidos y "homos" anteriores al homo sapiens 10 . Tal aproximación tiene algo de tentador ${ }^{11}$, pero temo que sea excesivamente fácil. Vamos a limitamos al texto tal cual.

\section{Intentos fallidos}

El primer intento humano fue hecho de barro, como en el Génesis. Sin embargo su figura se deshacía con las aguas. Una dificultad en la que no parece haber pensado el autor yahvista, cuya experiencia del poder de las aguas debía ser mucho más pobre. El segundo proyecto fue hecho de madera. Estos ya no se desharán pero, en cambio, son como palos: no hay manera de "animarlos". Se multiplicarán, poblarán la tierra, incluso hablarán, "pero no tenían alma ni entendimiento, no se acordaban de su Creador, de su Formador" (p. 40).

Notemos cómo el alma humana consiste para el autor maya en el recuerdo del Creador. Y notemos, por contraposición de los dos intentos, la profunda percepción de la antinomia antropologica: si su materialidad es floja, no resiste: pero si su materialidad es fuerte, no tiene alma. Es una de esas cosas de las que P. Ricoeur diría que los símbolos "dan que pensar".

Vendrá entonces el tercer intento, ya en el capftulo 3 de la segunda parte. Esta vez el hombre será hecho de diversas plantas, con la novedad de que aparece la diversidad sexual, y hay una planta distinta en el material de cada sexo: el árbol del pito para el varón y la espadaña para la mujer. Estos "homínidos" llegarán hasta una cierta artesanfa; "pero no pensaban, no hablaban con su Creador y su Formador"; por lo que también van a ser castigados como los anteriores. Diremos una palabra sobre estos castigos, no sin antes volver a notar la profunda definción del hombre que está implícita en todo este proceso: el hombre se define por la capacidad de hablar con Dios.

\section{Castigos}

El castigo consiste en un diluvio, lo cual llama la atención por su semejanza literal con el Génesis 12. Se sospecha que el diluvio no proviene de ила interpolación cristiana, sino de algún recuerdo o tradición histórica antigua. La diferencia es que, en la Biblia, el diluvio tiene lugar dentro de la historia y por el pecado de la historia, no en una especie de prehistoria anterior al hombre.

Pero el castigo consiste también en una rebelión de las obras de los hombres-de-planta contra sus autores: las tinajas, los comales, los platos, las ollas, las piedras de moler y hasta los perros, se levantan contra sus dueños: "mucho mal nos hacían.... éramos atormentadas por ustedes.. Ahora probarán nuestras fuerzas" (p. 41). Otra vez cabe sospechar que, si en la Biblia dominaba más el 
sentido de la historia, en el Popol Vuh domina más el sentido de la obligación que tiene el hombre de respetar la naturaleza.

Finalmente hay que añadir que, a pesar del castigo, no perecen todos esos seres prehumanos. Muchos de ellos perviven y suministrarán personajes para toda una serie de historietas o tradiciones recogidas a continuación, en las cuales aparecen en contacto con una complicada serie de figuras o dioses intermedios (rayos, duendes del bosque...), algunos de los cuales parecen ser divinizaciones de los oficios existentes en los tiempos de la redacción del Popol Vuh. Buscando paralelismos no será difícil evocar aquí la exuraña alusión de Génesis 6, 4 a "los gigantes o héroes de antaño", aunque el Génesis sea en este punto mucho más sobrio.

\section{Mitologías y etiologías prehistóricas}

En cualquier caso, la segunda parte del libro constituye un enorme paréntesis, que tiene un carácter mucho más cultural que religioso y en la que, por eso, no vamos a entrar, porque ello requeriría una preparación de la que carezco en absoluto.

Piensa Girard (y es uno de los puntos que se le ha discutido), que esas creaciones anteriores al hombre son una mitificación de etapas "prehistóricas" (o anteriores al pueblo quiché): la de la caza (aparición de los animales), la de agricultura (presencia del barro, del agua, y necesidad de que el hombre sepa resistirles); la de un cierto matriarcado vinculado al auge de la horticultura y a la primacla del frijol sobre el malz... Esa especie de prehistoria prepara la aparición del pueblo quiché, como ocurre en los once primeros capítulos del Génesis hasta que aparece Abrám; y no parece tener otra finalidad que ese encuadre. A una mentalidad occidental puede llamarle la atención la presencia importante del juego en toda esa historiogénesis: otro detalle que tampoco aparece en el Génesis, donde domina una mentaljdad más productivista (que acaba en la soberbia de la torre de Babel).

Pero, repito, esa prehistoria es anterior no sólo a la aparición del pueblo (como en el caso del Abrám bíblico), sino simplemente anterior a la creación del hombre tal cual. Por eso es proporcionalmente mucho más larga, y el autor parece interrumpir su narración para intercalar la historia de Hunahpú e Ixbalanqué, con unos criterios muy diversos de lo que sería una lógica narrativa occidental (libro I, caps. 6ss y libro II)13. No seguiremos paso a paso esas historias, ni las genealogias que las acompañan, pero sí quisiera señalar que aquf es donde tiene lugar la aparición de los astros que antes echábamos de menos en la comparación con Génesis 1. Puede que esto sea debido al paralelismo entre el curso del sol (aurora, cenit, ocaso) y el de la vida e historia humanas. El poema con todo da otra doble razón: la necesidad de luz en aquella tierra ya constituida y parcialmente poblada14, y la necesidad de acabar con el orgullo del 
guacamayo ("un ser orgulloso de sí mismo que se llamaba Vucub-Caquix") que se figura ser él el sol. Al revés de la serpiente brblica, el animal que podría ser enemigo del hombre es derrotado antes de aparecer éste y para que aparezca éste. Su destino deberá servir para que "así hagan todos los hombres, porque no se deben envanecer por el poder ni la riqueza" (p. 43). ¡Página optimista que parece relegar el "pecado original" a la prehistoria humana!

Sin entrar, por tanto, en esas leyendas, enumeraré sólo algunos rasgos que podrían tener su paralelo con otros del Génesis.

1) La presencia de un árbol, no prohibido pero cuyos frutos son calaveras (las cabezas de los padres de los héroes). Es también una mujer la que come del fruto de ese árbol. Pero no para ser castigada, sino para quedar encinta de Hunahpú e Ixbalanqué. En esta especie de "concepción virginal", la heroína no es creída y es castigada a sacarle el corazón (primera alusión a esa discutida práctica), salvándose por engaño (p. 64 ss).

2) Hay una especie de "multiplicación del maíz" por la heroína Ixquic que, a un lector de la Biblia puede recordarle la multiplicación del pan, tanto en el profeta Eliseo como en Jesús. Pero Ixquic no lo hace para alimentar a hambrientos, sino en defensa propia: para cumplir lo que le ha exigido su suegra (p. 67).

3) Aparece la envidia del otro por la experiencia de que el otro "me quita sitio" (p. 69 ss). Podría haber aquí un trasunto del mito de Caín y Abel. Pero en el Popol Vuh no está expresado como rivalidad entre los dos hermanos, sino como mito de clases sociales: los envidiosos sólo se ocupaban en tocar la flauta y cantar, los envidiados se ocupaban en la caza con las cerbatanas 15 . Pero, al revés que en el Génesis, la leyenda concluye con la victoria de los inocentes, para que sirva de ejemplo. En general, el Popol Vuh me parece, respecto de la historia, más optimista que el Génesis. De hecho, y corno se percibe en el episodio del azadón mágico, Hunahpú e Ixbalanqué son tremedamente astutos y engañadores como el Ulises griego, pero para luchar contra el reino del mal de Xibalbá. Por eso no aparecen en esta parte del Popol Vuh ni la torre de Babel (Génesis 11: maldición del progreso), ni el episodio de Noé y sus hijos (Génesis 9, 18ss: deshumanización de la bebida), ni la dura sentencia de Génesis 6, 6: "se arrepintí Yahvé de haber creado al hombre"16. Pero tampoco la fidelidad de Dios ante la maldad humana, simbolizada en el arcoiris: "no volveré a maldecir la tierra a causa del hombre" (Génesis 8, 21).

4) Asistimos también a una convivencia con los animales de todos esos "hombres", que puede recordar al pararso terrenal del Génesis, aunque no siempre es del todo armónica. De ella brota la explicación de algunos rasgos de los animales (vg. la cola corta del venado y el conejo, o la cola sin pelo del ratón: pp. 74-75) y también de algunos dichos del pueblo quiché como "ya oscureció el zopilote" (p. 88). 
5) Ya he hecho notar cómo me llamaba la atención la presencia del juego, mucho mayor que en el Génesis. Ahora, la aslucia de los dos muchachos para recuperar los guantes, el aro y la pelota del juego, escondidos por la abuela, parece el reflejo de una escena de la más pura vida cotidiana. Probablemente se reflejan también rivalidades entre diversas aldeas en el juego de pelota (p. 75 ss). Recordemos no obstante que todo esto ocurre, no a los hombres, sino a esa especie de "prehomínidos" que eran los "hombres de palo" como dice expresamente el texto (p. 80).

6) En el episodio del mosquito (cap. VIII, p. 80ss) llama también la atención la importancia otorgada al nombre. Al igual que en la mentalidad semita, conocer el nombre del otro es adquirir poder sobre él. Es así como los muchachos se libran de los señores de Xibalbá.

7) En la narración de la muerte de Hunahpú e Ixbalanqué sorprende la presencia de alusiones que parecen muy fantásticas, pero que, en realidad, reflejan actos de sugestión e ilusionismo que, según parece, eran muy conocidos de los mayas 17 .

8) Al final de la historia de estos dos hermanos resulta que los hijos redimen la muerte de los padres, pasando los mismos sufrimientos que ellos, pero retornando a la vidal8. Y sin embargo, el lector no sabe si, en esa victoria final, no hay una justificación de las "clases sociales", en la que la clase baja es tal como castigo de sus pecados anteriores 19.

Muchas de estas observaciones son de carácter más cultural que propiamente religioso. Por eso repito lo que acabo de decir: quizás el parangón más interesante habria de hacerse con los otros mitos-matriz de occidente, como puede ser la Odisea de Homero, que ha dado lugar a toda esa importantísima reflexion crítica de la historia europea, conocida como Dialectica de la llustración20.

En cualquier caso, este segundo libro es anterior al tiempo, puesto que, al acabar él, al comienzo del libro tercero es cuando nos encontramos en "el principio de cuando se dispuso hacer al hombre y cuando se buscó lo que debla entrar en la carne del hombre" (parte III, cap. 1, p. 101).

\section{La creación del hombre}

Creo que es en este capftulo donde más fáciles brotan los paralelismos. Por eso voy a limitarme a enumerarlos, sin más introducción.

1) Al igual que en el Génesis, el hombre aparece como término de la creación: para que "se termine la obra" (p. 101).

Pero, a diferencia del Génesis, el hombre surge "para sustentar y mantener a los dioses" (ibid.). Este es un rasgo bastante común a casi todas las mitologias antiguas, presente también en poemas mesopotámicos, como el Atra Hasis (s XVIII a. 
C.) etc., y del que la Biblia intentó apartarse. Es por eso coherente que ya los primeros padres sean "sacerdotes y sacrificadores" (vg. pp. 104, 113): el sacerdocio no aparece como una necesidad de llegar hasta Dios, sentida por los hombres a lo largo de la historia, sino como una necesidad de los mismos dioses.

2) El hombre es creado de maíz, no de barro como en el Génesis. La lógica subyacente parece ser que el hombre se alimenta sobre todo de maíz: luego ¡de eso debe estar hecha su carne!:

moliendo entonces las mazorcas amarillas y las mazorcas blancas, hizo Ixmucané nueve bebidas, y de este alimento provinieron la fuerza y la gordura y con él crearon los músculos y el vigor del hombre... De malz amarillo y de maíz blanco se hizo su came; de masa de maíz se hicieron los brazos y las piernas del hombre. Unicamente masa de maíz entró en la carne de nuestros padres (p. 102).

Dentro de su primitivismo, pocas veces se ha cantado con más belleza la gratitud del hombre hacia su sustento. La lógica que domina Génesis 2 no es ésa, sino la de la poquedad del hombre: fue hecho de barro porque es tierra (adamah); y por eso su castigo consistirá simplemente en que "vuelvas al polvo del que naciste" (Génesis 3, 19). Dos acentos diferentes y dos lógicas complementarias.

3) De acuerdo con la lógica anterior, resulta lógico que el hombre se autorreconozca satisfecho, por comparación con los animales, hasta el punto de magnificar sus origenes privándose de la limitación espacial:

hombres fueron; hablaron, conversaron, vieron y oyeron, anduvieron, agarraban las cosas; eran hombres buenos y hermosos y su figura era figura de varón. Fueron dotados de inteligencia; vieron y al punto se extendió su vista, alcanzaron a ver, alcanzaron a conocer todo lo que hay en el mundo. Cuando miraban, al instante veían a su alrededor y contemplaban en torno a ellos la bóveda del cielo y la faz redonda de la tierra.

Las cosas ocultas 21 las veían todas sin tener primero que moverse; en seguida velan el mundo y asimismo desde el lugar donde estaban lo vefan. Grande era su sabidura... (102-103).

Espléndido párrafo que evoca la misma admiración del hombre por sí mismo que se refleja en el salmista: "lo hiciste poco inferior a los ángeles; le coronaste de gloria y dignidad" (Sal 8).

4) Por todo ello, los hombres agradecen sentidamente a los dioses: "en verdad os damos gracias dos y tres veces" (p. 103). Pero, a pesar de esa honesta gratitud, su grandeza va a suscitar la envidia de los dioses.

He aqul un tema presente en casi todos los mitos antropologicos: la sensación de esa quasi-divinidad del hombre (la "imagen de dios" de Génesis 1, 26), 
y la deducción de que la otra dimensión doliente del ser humano habrá de explicarse por envidia (o, en el mejor de los casos, castigo) de los dioses.22 Por eso, el equivalente a los mitos de la calda acontece aqul, no por desobediencia o soberbia de los hombres sino por envidia divina. Y el "castigo original" no proviene de una prohibición quebrantada (como en Génesis 2, 17), sino de las cualidades manifestadas. Pero, en lógica con ello, ese castigo será más una limitación que una pena (al revés que en Génesis 3, 14-19):

No está bien lo que dicen nuestras creaturas... todo lo saben, lo grande y lo pequeño.... ¿Qué haremos con ellos? Que su vista sólo alcance a lo que está cerca, que sólo vean un poco de la faz de la tierra... ¿Acaso no son por su naturaleza simples creaturas y hechuras nuestras? ¿Han de ser ellos también dioses?...

Así dijeron: Refrenemos un poco sus deseos, pues no eslá bien lo que vemos. ¿Por ventura se han de igualar ellos a nosolros sus autores, que podemos abarcar grandes distancias, que lo sabemos y vemos todo? ... Entonces el Corazón del cielo les echó un vaho sobre los ojos, los cuales se empañaron como cuando se sopla sobre la luna de un espejo. Sus ojos se velaron y sólo pudieron ver lo que estaba cerca, sólo esto era claro para ellos (pp. 103104).

Es conocido el esfuerzo de la Biblia por desmitificar este tipo de mentalidad (que responde a una profunda experiencia humana). Para la Biblia, la desgracia del hombre proviene de una desobediencia; y una desobediencia irracional puesto que lo que se le prohibía era comer "del árbol de la experiencia del bien y el mal" (Génesis 2, 17)23. El hombre quebranta ese mandato porque cree que esa experiencia es el camino para "ser igual a Dios" (Génesis 3, 5). Este es su error radical puesto que, evidentemente, a Dios no se llega por la experiencia del bien y del mal24.

El Popol Vuh parece atisbar algo de eso mismo, cuando habla también de "refrenar un poco los deseos". Pero, en consonancia con su tono optimista, se queda más en la grandeza del hombre como causa del miedo de los dioses, y se atiene a la más elemental contradicción de esa ilimitación humana, que es la limitación espacial, la vista del hombre ya no abarcará todo el mundo, como se nos había dicho antes.

En cualquier caso, la experiencia de esa paradoja humana (que el cristiano confiesa como "Tu Imagen empañada por la culpa"), se reencuentra aquí en otra preciosa expresión: el hombre es "como la luna empañada de un espejo" (p. 104).

5) Otro punto de comparación: al igual que en el Génesis, la mujer aparece cronológicamente después del varón.

Me parece claro que, tanto en el Popol Vuh como en el Génesis, esia poste- 
rioridad cronológica no pretende (ni puede) fundamentar ninguna inferioridad en la intención de los autores, sino sólo expresar la alegría desbordante del varón en la mujer y en el encuentro con ella ( qque son cronológicamente ulteriores al hecho de nacer!). Una alegria que -en ambos textos- no halla mejor forma de expresarse que el recurso al factor sorpresa, introducido mediante el despertar del sueño. Es aqư muy fácil la comparación y basta yuxtaponer el texto del Popol Vuh ("allí estaban sus mujeres cuando despertaron, y al instante se llenaron de alegría sus corazones a causa de sus esposas", p. 104), con el de Génesis 2, 23: "ésta sl que es hueso de mis huesos y carne de mi carne. Su nombre será hembra porque forma parte del hombre. Por eso un hombre abandona padre y madre y se junta a su mujer y se hacen los dos una sola persona"25.

6) El último punto que queda para comentar es el que marca una mayor diferencia material. En el Popol Vuh no es creado un único ser humano, sino cuatro.

Me temo que sería concordismo demasiado fácil leer esta afirmación en clave científica poligenista. Y me pregunto hasta qué punto esta concepción (que evita los problemas referentes al incesto y la endogamia), no puede rebajar algo la afirmación de unidad del género humano (la cual, de todos modos, quedará a salvo por la procedencia de los cuatro hombres de un mismo Creador). De acuerdo con eso, la "primera" mujer son también cuatro. A partir de aquí comienza la aparición de las diversas tribus del mundo conocido: yaquis, toltecas, olmecas..: "ellos engendraron a los hombres, a las tribus pequeñas y a las tribus grandes, y fueron el origen de nosotros las gentes del Quiche" (p. 104).

En el Génesis, la diferencia de razas no arranca de la creación, sino de los hijos de Noe $(6,9 s s)$. Y si la preocupación genealógica es común a ambos libros, también lo es el asombro por la diversidad y por el problema del otro: "hombres negros y hombres blancos, hombres de muchas clases, hombres de muchas lenguas, que causaba admiración oirlas" (p. 105). Y, con este asombro, la sensación de que la multiplicación implica la pérdida del "centro" (que son lógicamente los quichés), la tentación de menosprecio al otro, y la convicción de la verdad exclusiva del propio modo de ser y la propia religiosidad:

No se sustentaban ni mantenfan a su Dios; solamente alzaban las caras al cielo y no sabían qué hablan venido a hacer tan lejos...

Hay generaciones en el mundo, hay gentes montaraces, a las que no se les ve la cara; no tienen casas, sólo andan por los montes pequeños y grandes como locos. Asi decían despreciando a la gente del monte (p. 105).

Mientras que, los que asf hablaban:

Una misma era la lengua de todos. No invocaban la madera ni la piedra, y se acordaban de la palabra del Creador y Formador, del Corazón del Cielo, del 
Corazón de la tierra (p. 105).

Es claro que la historia de Cam en Génesis 9 participa de esa misma tentación. Aunque en el Génesis, esa maldad de la diferencia (como también la confusión de lenguas por la torre de Babel en Génesis 11), brotan para su autor en el decurso mismo de la historia humana, sin remontarse a una multiplicidad inicial. Estas me parece que serían las semejanzas y las diferencias en este punto.

\section{Entrada en la historia}

Los capitulos siguientes son ya de menor interés para el té́logo, aunque deben tenerlo grande para el etnólogo, puesto que parecen mostrar el origen común de todos los pueblos de Guatemala y muchos de México hasta Yucatán. Asistimos a una dispersión de todos los pueblos y uribus que -según el Popol Vuh- se produce para buscar, no habitat o alimento, sino objetos de culto26. El pueblo quiché debió emigrar también hacia (o desde) el norte, encontrándose con pueblos de lengua y religión distintas y de menor desarrollo. Por eso, en la narración de esta dispersión tiene lugar una clara aparición de la multiplicidad de Idolos tribales, así como una nueva babel lingüística que, de todos modos, no es fruto de la soberbia, sino de la dispersión.

\section{La conquista del fuego}

Quizá el episodio de más interés para nosotros es el del fuego: pues nos remite al famoso mito griego de Prometeo, que robó el fuego a los dioses y fue castigado por Zeus. El milo pone de relieve tanto la importancia del fuego en el progreso humano, como la envidia de los dioses ante ese progreso. Ese mito tan lejano tiene aquí algunas variantes que no dejan de coincidir con el mito griego en marcar la gran importancia del descubrimiento del fuego. Este no fue un robo, sino un regalo a los primeros padres del Dios Tohil, citado expresamente como el dios de los quichés 27.

Los pueblos de Vucamag se presentan entonces ante los primeros padres a pedirles su fuego, porque estaban helándose de frío. Pero éstos se lo niegan (¿es ello una constatación de que la riqueza y el progreso material vuelven al hombre posesivo y avaricioso?):

- No nos causa vergüenza venir ante vosotros a pediros que nos deis un poco de vuestro fuego, dijeron al llegar. Pero no fueron bien recibidos. $Y$ entonces se llenó de tristeza el corazón de las tribus (p. 108).

Las tribus lamentan entonces su separación y su lengua diferente de la de los primeros padres. Mientras tanto, un mensajero de Xibalbá (¿el mundo infernal?) se aparece a los padres y les aconseja dar el fuego a las otras tribus, a cambio no de algo para ellos mismos, sino de algo para los dioses. Así sucede en una 
nueva embajada: las tribus piden misericordia y ofrecen dinero a cambio, Los padres rechazan el dinero y preguntan a Tohil qué es lo que han de pedir. He aqui la respuesta de Tohil:

- ¿Querrán dar su pecho y su sobaco? ¿Quieren sus corazones que yo, Tohil, los estreche entre mis brazos? Pero si asl no lo desean, tampoco les daré su fuego, respondió Tohil ... Y ésta era la abertura que habia dicho Tohil: que se sacrificaran a todas las tribus ante él, que se les arrancara el corazón del pecho y del sobaco (p. 110: caps. 5 y 6)

La alusión a los sacrificios humanos me parece inequívoca28. Me asegura un alumno que ésta es una interpretación trasnochada y que el corazón alude sólo a la intimidad de la persona. No tengo argumentos para aceptar esa afimación. Sólo puedo añadir que cuál sea la interpretación correcta es algo muy distinto de cuáles fueron las dimensiones de la historicidad de esa práctica la cual, según algunos historiadores, sólo fue real entre los mayas del Yucatán (aunque, hace años, otro alumno mexicano me negaba esto muy tajantemente). ¡Estamos ante mitos etiológicos y no ante historiografía documental! Tampoco debería ser rechazada su historicidad sólo por el hecho de que hoy parezca una práctica denigrante o porque, efectivamente, fuera manipulada por los conquistadores para justificar la conquista. Como ya respondio a esto Bartolomé de las Casas, era mucho menos malo sacrificar hombres al destinatario de una práctica religiosa, que sacrificarlos al dinero como hacían los españoles29. En todo caso, la única manera de evangelizar esa práctica inhumana era la manera bßblica y no la de los españoles: anunciar a un Dios que no quiere el holocausto del hombre, pero bendice largamente a quien le manifiesta esa actitud de entrega (ver Gén 22, 12-18), no a un Dios que "castiga" ese error de sus fieles entregándolos en manos de los conquistadores.

Las interpretaciones del texto no implican pues, necesariamente, juicios de valor. Sí cabe notar, en cambio, otra posible comparación con el texto bíblico. Según éste, la tecnología no es un regalo de los dioses a los hombres para que éstos les sirvan (como ocurre por ejemplo en el poema babilónico del azadón, del s. XVIII a.C.): es simplemente obra de los hombres30; pero, precisamente por esto, el progreso corrompe más al hombre hasta hacerle concebir el proyecto de la torre de Babel. Otra vez encontramos que la Biblia es más "secular" o más mundana: deja más autonomía al hombre pero también, quizás por eso, es más pesimista.

\section{Monumentos de pueblos}

El resto de la historia va ya focalizándose mucho y se aparta de los objetivos de nuestro trabajo. El movimiento migratorio da lugar a la aparición de innumerables tribus, nombradas todas en el poema e identificadas hoy varias de ellas. Los cuatro padres del pueblo quiche (los primeros hombres) que también hablan 
emigrado hacia el Norte, deciden regresar a su tierra de origen, quizás por los problemas surgidos a raíz de los sacrificios humanos 31 . En este retomo asistimos a un paso entre las aguas a pie enjuto, que evoca el episodio del Exodo, y que también sirve además como razón toponf́mica32.

De este retorno me parecen destacables tres rasgos.

a) En él parece tener lugar un "reencuentro" con el sol y un canto al astro rey, que ocupa el capítulo IX de esta tercera parte y que, más que con la Biblia, me pregunto si no podría ser comparado con otros semejantes sudamericanos: por ejemplo, si para los incas del altiplano el sol es sobre todo calor y posibilidad de vida, aquí el sol es bendecible sobre todo porque seca la tierra33, pero "no se soportaba su calor" (p. 115).

b) Destacable también de este retorno es la conciencia doliente por la separacion y diferencia entre los seres humanos: "AAy de nosotros!, en Tulan nos perdimos; nos separamos y allá quedaron nuestros hermanos mayores y menores. ¡Ay!, nosolros hemos visto el sol, pero ¿dónde están ellos ahora que ya ha amanecido?... Entonces se acordaron de sus hermanos mayores y de sus hermanos menores" (p. 116). Puede decirse que ésta es la primera vez que aparece el dolor en el Popol Vuh, y que su objeto es precisamente la división entre los hombres. Tal lamento tiene mucha razón de ser pues, en la parte siguiente, la última del poema, asisitiremos a la aparición de las guerras y los robos o las matanzas entre tribus.

c) Finalmente es destacable también el discurso del dios Tohil a los sacerdotes y sacrificadores, que da cuerpo al último capínlo de esta tercera parte y que, más allá del tema de la creación que ha ocupado a este artículo, serfa de interés para un estudio de la noción de sacrificio. Tohil promete la grandeza del pueblo pero, a su vez, se muestra como un dios desgraciado y necesitado de los hombres ("tened compasión de nosotros", p. 118).

De este modo, al igual que ocurre con los dioses griegos, la noción del sacrificio se "comercializa" y, a mi modo de ver, se ha degradado el halo religioso de algunas de las primeras páginas del Popol Vuh34. El estudio de la noción de sacrificio podria seguirse, ya en la parte siguiente, con la historia de las dos muchachas (Ixtah e Lxpuch) enviadas por las tribus vecinas para ver de seducir al dios Tohil, y que termina convertida en una leyenda etiológica sobre las pinturas en tela tan características de Guatemala.

\section{A modo de apéndice}

La última parte ya casi carece de interés para nuestro tema. El mundo está ya creado y ahora estamos en la historia de cada pueblo. Quizá valga la pena sugerir que, a semejanza con la Biblia y a diferencia de otros poemas mitologicos antiguos, el Popol Vuh no es sólo una cosmogonía, sino también el 
libro de la historia de un pueblo3s: incluso con su éxodo, su establecimiento y esplendor y desgracia posteriores. Forzando los paralelismos bろlicos podríamos titular esta última parte como "Libro de los reyes" (sobre todo si el libro brblico que lleva este nombre acabara en Salomón o pasara de Salomón a la invasión de Israel por el imperio asirio-babilonio).

Esta historia se prolonga por catorce generaciones. Su primera parte es historia política: asistimos a la muerte tranquila de los cuatro primeros padres y a la pervivencia del pueblo: un pueblo amenazado por muchos vecinos, los vence a todos, los somete a vasallaje y se engrandece. Se pasa de las guenras a la paz y prosperidad; y este proceso justifica la mayor organización del pueblo: la aparición de reyes y señores. Pero la prosperidad también engendra divisiones (simbolizadas por las peleas a propósito de las dotes de las mujeres o en los banquetes de boda). $\mathrm{Y}$ las divisiones acaban en una cierta feudalización (veinticuatro señores) y hacen necesario un poder mayor para la monarquía, en la cuarta generación, para preservar la unidad36.

Asistimos también a la aparición de las ciudades y fortificaciones de la época, y a la curiosa aclaración al lector, de que aquel pueblo se engrandeció no por afán de dominio, sino por necesidad de defenderse ${ }^{37}$, en claro contraste con lo que había dicho del guacamayo: que su única ambición era engrandecerse y dominar. Incluso se nos da aquI una justificación diferente de los sacrificios humanos, que ahora serán precisamente el casligo de los vencidos en guerra: "de esta manera nacieron los sacrificios de los hombres ante los dioses, cuando se libró la guerra de los escudos" (p. 135).

A la historia política sigue una rápida pincelada religiosa (cap. XI): la aparición y los nombres de los templos (que comparten la designación genérica y universal de "casa del dios"), la práctica intercesora del ayuno y la continencia, así como el texto de una oración de intercesión para esas circunstancias. Semejantes ofrendas eran "el precio de la vida feliz" (p. 143).

Y finalmente, la trayectoria política y religiosa va acompañada por una larga lista generacional de los diversos reyes y familias nobles. Ya he insinuado antes cómo el Génesis manifiesta un interés parecido por las largas genealoglas. Ahora señalaré sólo que, en la duodécima generación aparecen los españoles: "éstos eran los que reinaban cuando llegó Donadiú y fueron ahorcados por los castellanos" (p. 145). De modo que los reyes de la catorceava generación ya se van a llamar "Don Juan de Rojas y don Juan Cortés".

No hay pues una división interna y una degeneración de la monarqua, como en los reyes bßblicos (tampoco existe la profunda sospecha teológica de la Biblia ante la monarquia y el poder absoluto)38: por eso he dicho que es como si pasara de Salomón a la invasión por los imperios semitas.

Pero, de este modo, el libro que se caracterizaba por el optimismo y la poca 
presencia del dolor, va a terminar trágicamente. Una tragedia que sólo se insinúa, con llamativa sobriedad, por la aproximación de estas dos frases muy cercanas, separadas por apenas tres páginas de listas de generaciones de reyes y señores:

Así fue el principio de su engrandecimiento y del engrandecimiento del Quiché (p. 144).

Así pues se han acabado todos los del Quiché que se llarna ahora Santa Cruz (p. 147: frase con que concluye el libro).

\section{Conclusiones}

1) Lo primero que suscilan estas aproximaciones es una rellexión sobre la posibilidad de una antropología universal. Aunque mi objetivo primario era la comparación con el libro del Génesis, por el camino surgían con facilidad acercamientos a otros mitos, mesopotámicos o griegos. Creo que no sería estéril hacer un esfuerzo semejante de comparación con otros textos incluso del oriente más lejano, por ejemplo de los Vedas (Bagavad-Ghita etc.). En un mundo que va convirtiéndose cada vez más en "aldea global", me parece muy importante subrayar las posibilidades de una antropología universal y los rasgos comunes de la experiencia humana, a pesar de las evidentes diferencias, condicionamientos y variantes entre los hombres. $Y$ en un mundo que, a la vez que reduce sus dimensiones, se encuentra cada vez más amenazado por fundamentalismos racistas, culturales o xenófobos, la urgencia de esta tarea parece evidente.

Atendiendo al recorrido de este artículo, me han llamado la atención dos rasgos de esa experiencia humana común en los textos comparados: en primer lugar, la dialéctica del hombre, que es a la vez maravilla y miseria, grandeza y pequeñez, armonfa entrevista y armonía imposible. Lo que suscita la pregunta por la razón de esa paradoja y los caminos de su superación.

Y en segundo lugar lo serio de la "experiencia de la alteridad" o del problema del otro, ese otro (individual, cultural, racial, sexual) que, como escribió muy bien $P$. Ricoeur, me provoca "el sentimiento de que la cantidad de realidad que soy yo deja fuera de sl posibilidades inmensas de humanidad, que realizan los otros y no yo"39, y por eso se convierte en tentación de dominio o llamada al respeto. La oposición a toda apropiación privada del poder y de sus medios, y la necesidad de devolverlo a la totalidad humana: al pueblo (con el imperativo de liberación que ahf se expresa), se convierten en rasgos de una antropologla universal. Y el problema ético deberfa plantearse como aceptación de la propia limitación y como acogida del otro: como humildad y respeto, para decirlo con terminologfa de la ascética cristiana. No creo que haga falta volver sobre la presencia de estos dos rasgos en las páginas anteriores.

2) Cin̄endonos ahora a temas más específicamente teológicos, quisiera termi- 
nar con un par de observaciones que voy a proponer parafraseando dos observaciones de Rafael Girard. Si en la primera la Biblia puede culminar al Popol Vuh, en la segunda éste puede completar a la Biblia.

La primera se encuentra en el prólogo de su obra ya citada. Según Girard, el Popol Vuh "desvanece el prejuicio occidental (desde Montaigne a Descartes) de que el americano es el hombre sin historia". Si por historia sc entiende la memoria de cada pueblo, pienso que este arículo puede mostrar la verdad de esa afirmación (aunque la memoria de rodos los pueblos, también del judio, se pierda necesariamente en el mito). Es además una observación fundamental porque, como ha escrito varias veces J. B. Metz, la gran arma de todos los opresores es acabar con la memoria de los oprimidos, como modo de hacerles perder su identidad.

Y creo que hay ahí también una especie de "preparación evangélica", porque es a través de esa posesión de la historia como puede brotar la concepción cristiana de la dimensión teologal de la historia: que a Dios no hay que buscarlo exclusivamente (ni siquiera primariamente) fuera del trabajo de construcción de esta historia, que Jesús calificaba como "convertirse a la buena noticia del reinado de Dios".

O con otras palabras: en el Popol Vuh, tras la primera creación, Dios pasa de ser "Corazón del cielo" a "Corazón del cielo y Corazón de la tierra". Ese sería el presupuesto para el anuncio cristiano de Dios como "Corazón de la historia", que es lo que afirma la teologla cuando dice que la creación es un presupuesto de la alianza. Los valores que construyen la historia (justicia, paz, libertad, fraternidad, universalidad), no son valores ajenos al mundo y a la experiencia religiosa (como todavía pretenden los católicos de derechas), ni siquiera consecuencias éticas derivadas de ésta, sino la mediación privilegiada elegida por Dios para darse a los hombres. Y eso lo decimos de esta historia entregada en manos de los hombres y del principe de este mundo, pero a la cual Dios no ha querido renunciar, como lo mostró resucitando a Jesús de entre los muertos.

Escribe también Rafael Girard que en el Popol Vuh encontramos una "vinculación tan estrecha con Dios y el cosmos que quizá ninguna otra religión la superó bajo este aspecto" (p. 21).

Asf puede ser. Y ello marcaría una diferencia con el Génesis, cuya experiencia de la naturaleza era seguramente más negativa; y daría lugar a una dialéctica no hostil, sino complementaria.

Hemos dicho a lo largo de las comparaciones anteriores que la Biblia era más secular, más abierta a la autonomía del mundo y, por ello, menos "verticalista", a pesar de su enorme sentido de la trascendencia de Dios. Con otras palabras, al desacralizar al mundo, la Biblia lo pone en manos del hombre y abre así el espacio para el progreso técnico. Pero, al encontrar el mundo en sus 
manos, el hombre se enfrenta con él queriendo ser "igual a Dios" (Gen 3, 5); y el modo concreto como se realiza el progreso se convierte en el "pecado original" de la historia: la toma del árbol de conocer el bien y el mal40.

Esta mentalidad es ajena al Popol Vuh, del que ya subrayamos los aspectos más "verticalistas" de su religiosidad, la mayor comunión y respeto a la naturaleza y, derivando de ahí, su talante más optimista, y la llamativa presencia del juego frente a la productividad occidental $4 \mathrm{I}$.

Ambos aspectos son complementarios y sería fatal enfrentarlos. Tanto el cristiano como el indigenista necesitan hoy de los dos: pues el optimismo del Popol Vuh queda brutalmente enmudecido con las frases que hemos citado Iras la llegada de los españoles; y esa interrupción perdura hasta hoy ${ }^{42}$. Mientras que el delirio progresista ha quedado seriamente cuestionado por la terrible amenaza ecológica. El pesimismo de la Biblia sobre el hombre tenfa ahí su razón de ser.

Parodiando al salmista, es preciso que aquí "la naturaleza y la historia se encuentren, el progreso y la ecología se besen" (Sal 84,11). Pues si los verticalismos suelen acabar en idolatrías (tanto fuera como dentro de la Iglesia), los horizontalismos está amenazados de acabar en ateísmos, como ha sido el destino del occidente antaño cristiano.

Ambas son tareas para una teología latinoamericana de la creación ${ }^{43}$.

Notas

1. Las pocas referencias culturales que utilizaré en este artículo seguirán la obra clásjca de Rafael Girard, Esoterismo en el Popol Vuh, México 1984 (3 ed.) que tuvo una aceptación bastante general, aunque con algunas reticencias. También el excelente prólogo de R. Rodŕguez Dlaz a la edición de UCA Editores (San Salvador 1980, con traducción y notas de Adrián Recinos). Las citas de página que aparezcan en lo sucesivo sin otra referencia se refieren a esa edición de UCA Editores.

2. El subrayado es mío. Esta misma ambigiledad se refleja materialmente en el detalle de que el Popol Vuh está escrito en lengua quiché, pero ya con caracteres latinos.

3. "Cielo y tierra" es una de esas expresiones de contrarios que en el hebreo designan la totalidad.

4. Cfr. Girard, op. cir., p. 27.

5. "Que el agua se retire y desocupe, que surja la lierra"; "surgieron del agua las montañas" (p. 36).

6. "Hagamos al hombre" (Gen 1, 26). "Mientras meditaban que cuando amaneciera debia aparecer el hombre" (Popol Vuh, p. 36).

7. La identificación con el rayo no sé si permite una aproximación del número tres a la Trinidad o si ello serfa más bien un concordismo fácil. Pero las emanaciones de Dios parecen ser un atisbo de que la divinidad no es soledad absoluta.

8. Por esto se volverá a hablar de los animales en momentos sucesivos. Ahora baste notar la cercanfa con lo dicho sobre la creación por la palabra, en la Biblia.

9. "Por esta razon fueron inmoladas sus cames y fueron condenados a ser comidos y 
matados los animales"... (p. 38).

10. Igual que otros buscaron esa enser̃anza evolucionista en la frase del Génesis: "produzca la tierra...".

11. Incluso parece sugerida por el mismo texto: "dicen que la descendencia de aquéllos son los monos que existen ahora en los bosques; éstos son la muestra de aquéllos, porque sólo de palo fue hecha su carne por el Creador y el Formador. Y por esta razón el mono se parece al hombre" (p. 42).

12. Propiamente son dos diluvios, pero en Génesis también existe, junto al diluvio de agua, el posterior de fuego sobre Sodoma y Gomorra.

13. ¿Podria tratarse, como alguien ha sugerido, de dos tradiciones fundidas, como ocure en Génesis con los estratos yahvista, elohista, sacerdotal...?

14. "Habla entonces muy poca claridad sobre la faz de la tierra. Aún no hab́a sol" (p. 42).

15. El mito de Caín y Abel lo más que llegaría a reflejar no es una lucha de estratos sociales, sino de "profesiones": agricultores y ganaderos.

16. Por eso, como luego diré, un occidental se acuerda, a veces, más que de la Biblia, del protagonista de la Odisea de Homero (Ulises), que es otro de los mitos originarios de occidente.

17. Vale la pena recoger aquf el siguiente texto de Bemardino de Sahagún, citado en la edición que he manejado (p. 100, nota 39): “los mismos eran amigos de hacer embaimientos, con los cuales engañaban a las gentes, dándoles a entender ser verdadero lo que es falso, como es hacer creer que se quemaban las casas cuando no habia tal; que hacian aparecer una fuente con peces y no había nada sino ilusión de los ojos; que se mataban a sí mismos haciendo tajadas y pedazos sus carnes y otras cosas que eran aparentes y no verdaderas". Varios de estos ejemplos aparecen exaclamente en el Popol Vuh.

18. “Nosotros los que aqul veis somos, pues, los vengadores de los dolores y sufrimientos de nuestros padres: Por eso sufrimos todos los males que les hicisteis" (p. 95).

19. ..."Será rebajada la condición de vuestra sangre. No será para vosotros el juego de pelota. Solamente os ocuparéis de hacer cacharros, apastes y piedras de moler maíz. Sólo los hijos de las malezas y del desierto hablarán con vosotros. Los hijos esclarecidos, los vasallos eivilizados no os pertenecerán" (p. 95).

20. Cfr. T. Adomo y M. Horkheimer, Dialéctica de la llusiración, Madrid 1994. (La primera edición castellana, hacia 1969, se hizo en Argentina y llevaba el título ambiguo de "Dialéctica del iluminismo".)

21. Por la distancia.

22. Piénsese por ejemplo en esa maravilla de la literatura universal que son las tragedias griegas.

23. La Nueva Biblia Española traduce "el árbol de conocer el bien y el mal", traducción mucho más precisa que la habitual (ciencia del bien y del mal) puesto que el verbo hebreo yadah no tiene el sentido de un mero saber informativo, sino de un conocimiento experiencial, por comunión (acto sexual etc.).

24. A pesar de todo lo dicho, convendrá notar que ni la misma Biblia, con su esfuerzo desmitificador, se libra totalmente de algunos resabios de esa "envidia de los dioses", como muestra Gen 3, 22 que introduce la expulsión del paraiso. Aunque, por su ubicación al fin del relato, también cabe entender que Dios teme al hombre pecador, no al hombre creatura. 
25. Nótese de paso cómo, para la Biblia, la primera expresión de la dualidad sexual es la de la unión total, no la de la procreación. Esta sólo aparece en el capítulo siguiente $(3,20)$, cuando Adán le da el nombre de Eva (derivado del mismo verbo que significa vivir: por lo que su traducción literal sería: Vivificadora o Vitalidad). El texto citado del cap. IIl de la tercera parte del Popol Vuh parece más en consonancia con este modo de ver. Pero no ha elaborado esta problemática.

26. "Nuestras primeras madres y padres no tenlan todavla maderos ni piedras que custodiar... y ya eran muy numerosos todos los pueblos y la gente yaqui y los sacerdotes y sacrificadores... (por ello se dijeron):

- Vámonos a buscar a ver si están guardados nuestros símbolos, si encontramos lo que pondremos a arder ante ellos. Pues estando de esta manera no tenemos quien vele por nosotros" (p. 106).

27. Asf fueron llamadas las tres familias quichés y no se separaron porque era uno el nombre de su dios, Tohil de los quichés, Tohil de los Tamub y de los llocab; uno solo era el nombre del dios, y por eso no se dividieron las tres Jamilias quichés" (p. 107).

28. El texto que he utilizado aclara en nota, tras la primera frase del párafo citado: "es decir, entregar las victimas para que las sacrifiquen, al estilo mexicano, abriéndoles el pecho con el cuchillo de pedernal y ofrendando sus corazones a la divinidad" (p. 120).

29. También cabria aludir aquí a la famosa novela de Salvador de Madariaga, Corazón de piedra verde, que acepta la historicidad de los sacrificios, pero constata que, cuando los primeros mexicanos convertidos al cristianismo (precisamente para escapar de lo cruel de dicha práctica) van a España, se encuentran allí... con un solemne auto de fe de la inquisición, donde los hombres son quemados vivos. Otra vez: era mucho peor sacrificar los hombres a la ortodoxia que sacrificarlos a los dioses.

30. Cfr. Gen 4, 22: "Tubalcaín, forjador de herramientas de bronce y hierro".

31. Así lo interpreta la introducción de R. Rodríguez Dlaz al texto que he manejado: "la institución de sacrificios humanos entre los quichés provoco insurtecciones y disturbios que culminan en la resolución de abandonar en masa el territorio mexicano" (p. 26).

32. "Por esta razón fueron llamadas Piedras en hilera, Arenas arrancados, nombres que ellos les dieron cuando pasaron entre el mar, habiéndose dividido las aguas cuando pasaron" (p. 26).

33. Tohil, como el mexicano Quetzalcoatl, parecen estar identificados como dioses de la Iluvia.

34. He aquí la primera parte del discurso: "Verdaderamente aqứ serán nuestras montañas y nuestros valles. Nosotros somos vuestros; grandes serán nuestra gloria y nuestra descendencia por obra de todos los hombres. Vuestras son todas las tribus y nosotros, vuestros compañeros. Cuidad de vuestra ciudad y nosotros os daremos vuestra instrucción. No nos mostrêis ante las tribus cuando estemos enojados por las palabras de sus bocas y por su comportamiento. Tampoco dejêis que caigamos en el lazo. Dadnos a nosotros en cambio los hijos de la hierba y los hijos del campo y también las hembras de los venados y de las aves. Venid a darnos un poco de vuestra sangre, tened compasión de nosotros" (pp. 117-118).

35. Que fundamenta la posesion de la tierra.

36. "Se engrandecieron a causa de los señores prodigiosos". Y el mismo rey del que 
aquí se habla "no hizo esto para que hubiera un rey prodigioso; lo hizo solamenle para que hubiera un medio de dominar a todos los pueblos" (p. 138).

37. "Su grandeza era limitada. No hablan pensado en engrandecerse ni en aumentar. Cuando trataron de hacerio empuñaron el escudo... sólo para dar muestras de su imperio, en señal de su poder y de su grandeza" (p. 134).

38. Según Ricardo Falla, esta sospecha la habfa anticipado el Popol Vuh en la lucha que aquí hemos llamado prehistórica- de Hunahpú e Ixbalanqué contra el gran guacamayo (o Vubub Caquix). Cf. "Desmitologización por el mito. Fuerza de denuncia de la lucha de los héroes contra Vucub Caquix, en el Popol Vuh", en ECA, febrero 1979, 1051-58.

39. Finirud y culpabilidad, Madrid 1969, p. 218.

40. Sobre las condiciones de un progreso liberado de ese "pecado original" remito a lo que escribí en "Los pobres como lugar teol6gico", en la obra en colaboración El secuestro de la verdad, Santander 1985. También en Revista Latinoamericana de Teologia (1984), 275-308.

41. En estas conclusiones prescindo de toda la incidencia del mundo griego en la lectura que occidente hará de la Biblia. Para ello hay análisis útiles en la obra sobre la Ilustración citada en la nota 19.

42. Véanse los testimonios estremecedores de R. Falla, Masacres en la selva, Guatemala 1993.

43. Véase como ejemplo P. Trigo, Creación e hisıoria en el proceso de liberación, Madrid 1988. 